\title{
Applied Electrical Fields Polarize the Growth of Mycelial Fungi
}

\author{
By ANN M. MCGILlivRAY AND NEIL A. R. GOW* \\ Department of Microbiology, Marischal College, University of Aberdeen, \\ Aberdeen $A B 9$ IAS, UK
}

(Received 14 April 1986; revised 21 May 1986)

\begin{abstract}
Mycelial fungi generate endogenous electrical fields which are associated with polarized tip growth. Here we show that applied electrical fields can dramatically affect the polarity of growth of a variety of filamentous fungi including Neurospora crassa, Aspergillus nidulans, Mucor mucedo, Trichoderma harzianum and Achlya bisexualis. The precise behaviour of each fungus when exposed to an electric field was different; however the sites of germ tube formation and branching, the direction of hyphal extension and the frequency of branching and germination could all be affected. $N$. crassa and Ach. bisexualis grew and formed branches towards the anode while Asp. nidulans and M. mucedo exhibited tropisms towards the cathode. Galvanotropism of hyphae and branches of $T$. harzianum was in opposite directions. Germ tube formation from conidia of $N$. crass $a$ was highly polarized in electrical fields whereas fields of a similar strength had little effect on the polarity of germ tube formation in Asp. nidulans. Hyphae became aligned perpendicularly as they grew longer and as the field strength increased. It is suggested that this perpendicularly orientated extension relieves growth-inhibiting perturbations of the membrane potential in cells which had been aligned parallel to the field. These results are discussed in relation to the hypothesis that the polarity of hyphal growth is under electrical control.
\end{abstract}

\section{INTRODUCTION}

Extension of the hyphae and branches of mycelial fungi is restricted to a narrow zone at the extreme apex. In addressing the question of how hyphal growth is polarized, most studies have concentrated on the cytology and enzymology of this region. As a result we have detailed information showing that wall-synthesizing enzymes such as chitin synthase are active only at the apex and that the enzymes and new cell membrane for cell expansion are transferred to the tips in microvesicles (Grove, 1978; Trinci, 1979; Gooday, 1983). However, we are still far from understanding how polarized growth is established and maintained since we know little about how these vesicles are translocated and guided or how polarity is first generated.

Recent work has shown that the polarizing mechanism may relate to endogenous electrical fields and associated ion currents which flow around and through fungal hyphae during tip growth (Kropf et al., 1983; Armbruster \& Weisenseel, 1983; Gow, 1984; Horwitz et al., 1984). Positive ions flow into the tips of hyphae and branches during cell extension and outward from distal regions of the hypha. In Achlya bisexualis the ion circulation represents a flow of protons which probably results from the segregation of proton pumps and proton leaks in the cell membrane. The ion current in this organism is therefore a spatially extended chemiosmotic circulation (Kropf et al., 1984; Gow et al., 1984; Kropf, 1986). Interestingly, ion currents have been found to enter growing apical regions of a phylogenetically diverse group of organisms including the germinating eggs of brown algae (Jaffe, 1966; Robinson \& Jaffe, 1975), lily pollen germ tubes (Weisenseel et al., 1975) and plant roots and their root hairs (Weisenseel et al., 1979; Miller et al., 1986). The correlation between polarized growth and ion currents is further consolidated by observations showing that non-growing and non-polarized cells do not generate currents (Kropf et al., 1984; Gow, 1984; Kropf, 1986), and that localized ion currents enter cells 
at locations that precede and predict where new sites of polarized growth will occur (Weisenseel et al., 1975; Nuccitelli, 1978; Kropf et al., 1983).

If electrical currents and electrical fields are generated by cells growing in a polarized fashion, we can ask whether the application of electrical fields to biological cells influences their polarity. The results from studies of a wide range of cell types have shown that this is often the case. The sites of outgrowth from zygotes of Fucus, Pelvetia and Ulva (Lund, 1923; Peng \& Jaffe, 1976; Sand, 1973), spores of Equisetum and the common moss Funaria (Bentrup, 1968; Chen \& Jaffe, 1979) and pollen grains of Vinca (Marsh \& Beams, 1945) are all polarized in applied fields. A variety of animal cells including Xenopus neurites, myoblasts, neural crest cells and epithelial cells, quail neural crest cells and fibroblasts and fish scale cells migrate or form cell processes preferentially towards the cathode. (For a recent review see Robinson, 1985.) Taken together this information suggests strongly that there is an electrical dimension to the control of cell polarity.

To our knowledge the only fungal system that has been shown to be influenced by applied electrical fields is the outgrowth of hyphae from regenerating protoplasts of Schizophyllum commune, where hyphae were shown to be orientated towards the anode (De Vries \& Wessels, 1982). Here we describe experiments which show that applied electrical fields influence the germination of fungal conidiospores and the growth and orientation of hyphae and branches of the developing mycelium. A preliminary report of some of these results has been presented (Gow \& McGillivray, 1986).

\section{METHODS}

Organisms. Achlya bisexualis female strain T5 (14524) and Trichoderma harzianum 32173 were from the American Type Culture Collection. Neurospora crassa RL21a, Aspergillus nidulans G00 and Mucor mucedo Z43 $(+)$ were provided by C. L. Slayman (University of Yale, Conn., USA), A. J. Clutterbuck (University of Glasgow, UK) and the University of Aberdeen Culture Collection respectively.

Preparation of conidia and zoospores. Stock cultures of Ach. bisexualis were maintained on PYG medium, containing $\left(\mathrm{g}^{-1}\right)$ mycological peptone $(1 \cdot 25)$, yeast extract $(1 \cdot 25)$ and glucose (3), solidified with $2 \%(\mathrm{w} / \mathrm{v})$ agar. $M$. mucedo was grown on malt extract $\left(20 \mathrm{~g} \mathrm{l}^{-1}\right), T$. harzianum on potato dextrose medium $\left(36 \mathrm{gl}^{-1}\right)$ supplemented with yeast extract $\left(2 \mathrm{~g}^{-1}\right)$ and mycological peptone $\left(1 \cdot 2 \mathrm{gl}^{-1}\right)$ and $A$ sp. nidulans on media containing $\left(\mathrm{g} \mathrm{l}^{-1}\right)$ malt extract (20), yeast extract (2) and mycological peptone $(1 \cdot 2)$. N. crassa was grown on Vogel's minimal medium (Vogel, 1956) which contained $1.5 \%(\mathrm{w} / \mathrm{v})$ glucose. Mycelia were grown on agar in Petri dishes or $250 \mathrm{ml}$ Bellco flasks until the colonies covered the agar and formed conidia. Conidia were harvested by agitating the surface of colonies with sterile distilled water and hyphal fragments were removed by filtering the spore suspension through cotton wool in the mouthpiece of inverted sterile pipettes.

Zoospores of Ach. bisexualis were prepared as described by Gow et al., (1984) and then allowed to encyst over a period of $40 \mathrm{~h}$. Suspensions of zoospores were concentrated by gentle filtration through Nucleopore polycarbonate membrane filters $(50 \mathrm{~mm}$ diameter, $5 \mu \mathrm{m}$ pore size) until most of the sporulation medium was removed. Suspensions of up to $5 \times 10^{6}$ zoospores $\mathrm{ml}^{-1}$ could be produced by this method.

Preparation of gels and electrophoresis medium. Non-defined media of low ionic content were used. The low conductivity of the media $\left(<5 \mathrm{mS} \mathrm{cm}^{-1}\right)$ ensured that there was minimal heating of the medium and gel at high field strengths. Media for $N$. crassa, Asp. nidulans, $M$. mucedo and $T$. harzianum contained $2 \%$ (w/v) malt extract and 20 mM-potassium phosphate buffer, pH 6.5; that for Ach. bisexualis contained PYG medium in $10 \mathrm{~mm}-$ potassium phosphate buffer, $\mathrm{pH} 7 \cdot 0$. The ionic content of these media was mainly due to buffer, which was incorporated to prevent the electrolytic acidification of the medium during experiments.

Sterile electrophoresis medium $(13 \mathrm{ml})$ containing $1 \%(\mathrm{w} / \mathrm{v})$ electrophoresis-grade agarose (Bethesda Research Laboratories) was boiled and then cooled to $40^{\circ} \mathrm{C}$ in a water bath. To this, $1 \mathrm{ml}$ of a suspension containing $10^{5}-10^{7}$ conidia $\mathrm{ml}^{-1}$ or $2-5 \times 10^{6}$ zoospores $\mathrm{ml}^{-1}$ which had been preheated to $40^{\circ} \mathrm{C}$ was added. The agarose and conidia/zoospores were mixed and poured onto a gel plate to a depth of $2.5 \mathrm{~mm}$ and allowed to set. The gel holder and gel were placed in the electrophoresis cell and the reservoirs filled with electrophoresis medium. When buffered malt extract medium was used, one drop of silicone MS antifoam emulsion RD (Hopkins and Williams) was added for every $100 \mathrm{ml}$ of electrophoresis medium to reduce foaming at the electrodes during the application of the field.

Applied electrical field apparatus. Electrical fields were applied using a small DNA electrophoresis cell (Bio-Rad mini-sub cell) by a method based on that described by De Vries \& Wessels (1982). Electrophoresis medium was pumped over the gel between the electrode reservoirs and through a cooling coil, with a flow rate of $240 \mathrm{ml} \mathrm{min}^{-1}$. In our system $300 \mathrm{ml}$ of electrophoresis medium was required to complete the circulation and just cover the gel. 
Bent glass rods were placed across the gel surface so that the bent ends hung over the ends of the gel tray. These held the gel in place in the rapidly flowing medium. The fast circulation prevented the buildup of gradients of oxygen, $\mathrm{pH}$, nutrients or electrolytic by-products and allowed the temperature of the medium to be maintained at $25 \pm 1{ }^{\circ} \mathrm{C}$ by controlling the flow of tap water to the cooling coil. At field strengths of $40 \mathrm{~V} \mathrm{~cm}^{-1}$ it was often not possible to prevent some heating of the central sections of gels, and spores in this area sometimes failed to germinate. The buffer in the electrophoresis medium maintained a constant $\mathrm{pH}$ for at least $6 \mathrm{~h}$, even with the strongest fields. For longer experiments the electrophoresis medium was exchanged at $6 \mathrm{~h}$ intervals. Spores were either exposed to constant electrical fields until germination and growth had taken place or were allowed to germinate before the field was applied. At the end of an experiment the gel was removed and fixed in buffered $5 \%$ $(\mathrm{v} / \mathrm{v})$ formalin before examination.

Determination of the extent of polarization. Fixed specimens were observed within the gels using an Olympus CK inverted microscope (total magnification $\times 100$ ) fitted with a full-circle eyepiece reticule. The orientations of germ tubes, hyphal tips and branches with respect to the anode-cathode axis was determined with the anode designated as $0^{\circ}$. The percentage polarization was calculated from

$$
P(\%)=\sum \frac{\cos \theta}{n} \cdot \frac{100}{1}
$$

where $\theta$ is the angle made by the germ tube, branch or hypha to the anode-cathode axis and $n$ is the total number of angles measured (at least 300 in each experiment). Accordingly for a gel in which all specimens are aligned directly towards the anode, cathode or perpendicular, $P=100 \%,-100 \%$ and $0 \%$ respectively. Error bars are not shown but standard deviations for six samples were typically $\pm 3 \%$ or less.

\section{RESULTS}

\section{Germination of $N$. crassa in electrical fields}

Conidiospores of $N$. crassa were embedded in agarose and exposed to electrical fields between 0 and $40 \mathrm{~V} \mathrm{~cm}^{-1}$ (equivalent to 0 to $40 \mathrm{mV}$ per spore for conidia of diameter $10 \mu \mathrm{m}$ ). Increasingly strong fields increasingly polarized the location of germ tube emergence towards the anodic side of the spores (Fig. 1, Fig. 2a). The germ tube tip, once formed, continued to grow towards the anode. In the absence of a field but in otherwise identical conditions, the germ tubes emerged randomly (Fig. 2b). Galvanotropism towards the anode occurred independently of the direction in which the medium was pumped and was unaffected by the bubbling of air into the anodic or cathodic reservoirs of the electrophoresis cell. Also, there was no detectable difference in the $\mathrm{pH}$ of circulating medium at the two electrical poles. These controls indicate that the tropisms described are not related to gradients of oxygen, $\mathrm{pH}$, nutrients or electrode products.

Maximal polarization of germ tubes occurred at fields in and above $30 \mathrm{~V} \mathrm{~cm}^{-1},(30 \mathrm{mV}$ per cell diameter) where $P=72 \%$. If individual germ tubes were scored simply according to whether they grew in the anodic or cathodic directions (disregarding the precise angles they made to the field) this value corresponded to $93 \%$ of the germ tubes being directed towards the anode. The threshold value for fields influencing germination was at or below $2 \mathrm{mV}$ per cell.

The process of germination was also accelerated by electrical fields. Over $80 \%$ of conidia had formed germ tubes by $5 \mathrm{~h}$ in a field of $40 \mathrm{mV}$ per cell as compared with $8 \mathrm{~h}$ for the same amount of germination in the absence of any field. Germination was also more synchronous in applied fields as compared with controls (compare Fig. $2 a$ and $b$ ). This was reflected in relatively smaller standard deviations about the means for the germ tube lengths of specimens exposed to fields (e.g. $20.8 \pm 12.6 \mu \mathrm{m}$ for the experiment illustrated in Fig. $2 a$ ) compared with non-exposed controls $(21.8 \pm 30.3 \mu \mathrm{m}$ for Fig. $2 b)$. Germination of conidia of $N$. crassa was therefore hastened, synchronized and polarized by exogenous electrical fields.

\section{Hyphal growth and branching of $N$. crassa}

Once a germ tube tip was formed, it continued to grow towards the anode (Fig. 2a). Germ tubes that had formed in the absence of a field had random orientations but bent towards the anode after a field was applied (Fig. $2 \mathrm{~g}$ ). When hyphae were exposed to increasingly strong electric fields, orientation towards the anode was reduced (Fig. 3). The loss of polarization to the anode was not due to random growth in stronger fields but rather to reorientation of the hyphae 


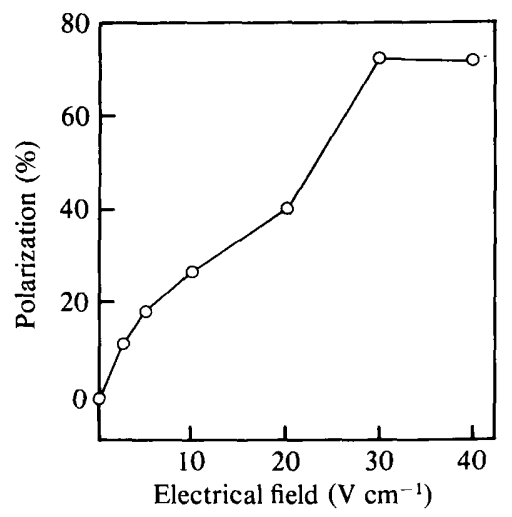

Fig. 1. Polarization of germ tubes of $N$. crassa towards the anode in exogenous electrical fields. The percentage polarization was calculated as described in Methods after $6 \mathrm{~h}$ exposure to the fields.

perpendicular to the field (perpendicular growth corresponding to $P=0 \%$ ). Perpendicularization increased with increasing field strength (Fig. 4). Reorientation of anodotropic germ tubes to the perpendicular plane occurred at a length that was proportional to the strength of the electrical field, i.e. shorter germ tubes were reorientated by stronger fields (Fig. 5). Thus germ tubes were initially polarized towards the anode, but then bent through $90^{\circ}$ to grow perpendicularly, the rapidity of the reorientation process being a function of the magnitude of the field and the length of the germ tube. Consequently older colonies had a spindle-like shape with the longitudinal axis perpendicular to the field (Fig. $2 c, d, h, i$ ). Perpendicular growth (discussed later) is interpreted as an adaptation which minimizes perturbations of the cell membrane potential which may be caused by the applied fields.

The influence of applied fields on branching of $N$. crassa shared many of the features described for germ tube formation. Branches were formed preferentially towards the anode (Fig. $2 c, d, e$ ), the degree of polarization being dependent on the magnitude of the field (Fig. 6). Branches were more strongly polarized than germ tubes for fields less than $30 \mathrm{mV}$ per cell although the maximum level of polarization of germ tubes and branches was similar. The weakest field capable of influencing branching was about $1 \mathrm{mV}$ per cell $\left(1 \mathrm{~V} \mathrm{~cm}^{-1}\right)$. In addition to influencing the direction of branch formation, applied fields also stimulated the rate of production of branches. In one experiment conidia were pregerminated in the absence of an electrical field, then exposed to a voltage gradient of $40 \mathrm{~V} \mathrm{~cm}^{-1}$ for $4 \mathrm{~h}$. Four times as many branches were formed over this period in the presence of the field compared to controls without an applied field (Fig. 2e,f). Apical branching, a characteristic feature of the early undifferentiated hyphae of $N$. crassa, was inhibited in all the electrical fields that were applied. As with germ tubes and mature hyphae, longer branches also changed direction to become aligned perpendicular to the field (Fig. $2 h, i$ ), thereby maintaining the spindle-shape appearance of older colonies.

\section{Effects of electrical fields on other fungi}

The galvanotropic behaviour of Asp. nidulans, M. mucedo and T. harzianum is summarized in Table 1. The fungi exhibited different responses to applied fields. With Asp. nidulans, germ tube emergence was not polarized by electrical fields but hyphae and branches grew towards the cathode (Table 1 ; Fig. $7 a, b$ ). The inability of the external field to influence the site of emergence of the germ tube may indicate that these conidiospores have some axis of polarity which predetermines where the germ tube emerges. We have not found any report of structural characteristics of conidiospores of Asp. nidulans and $N$. crassa which could help explain their differing responses to electrical fields. $M$. mucedo responded similarly to Asp. nidulans. Germ tubes emerged with a slight tendency to the anode but hyphae and branches were cathodotropic 

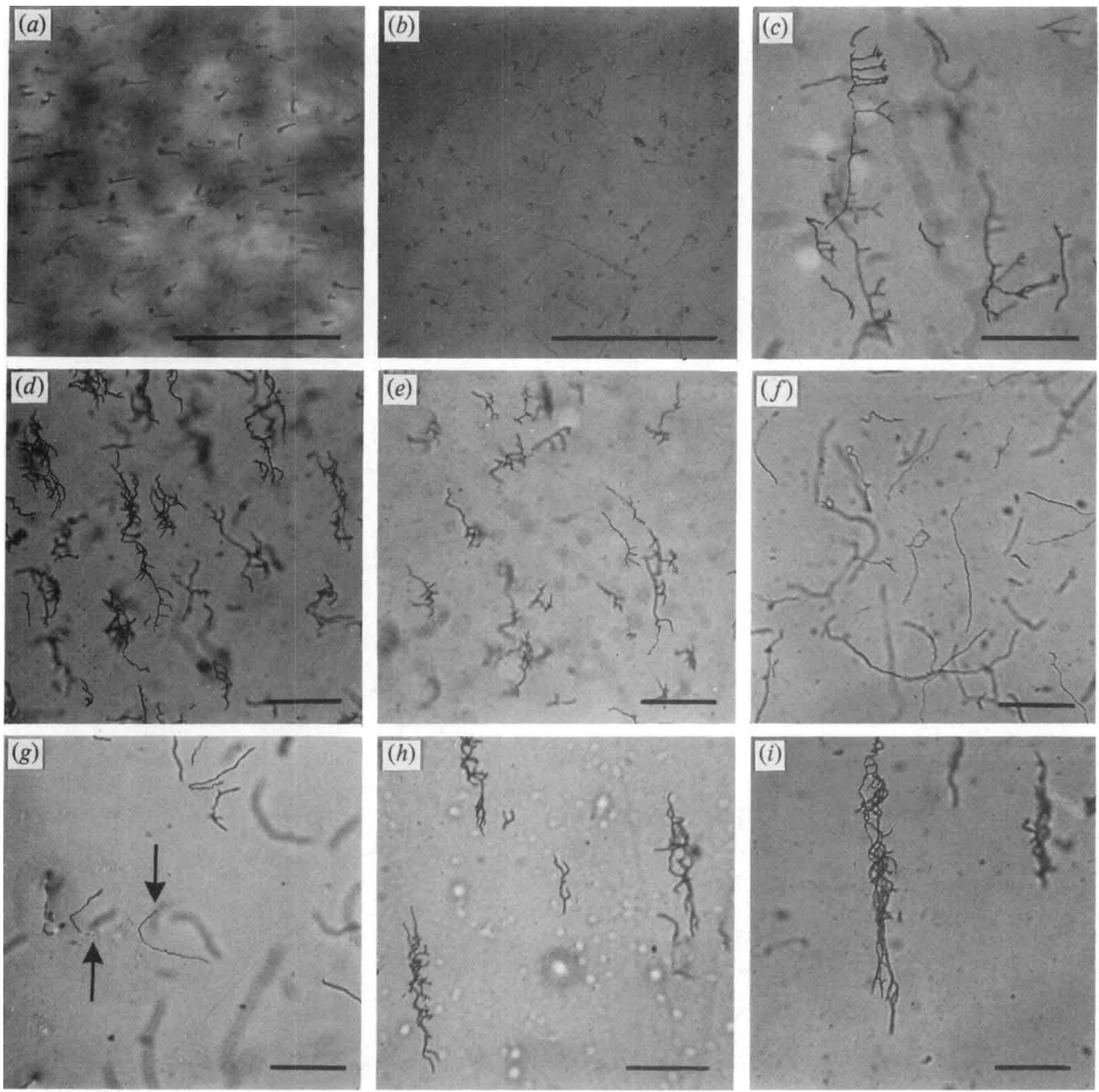

Fig. 2. Influence of exogenous electrical fields on the growth of $N$. crassa. In each photograph the anode is on the right and the scale bar represents $300 \mu \mathrm{m}$. (a) Polarized, synchronous germination of conidia induced by a field of $40 \mathrm{~V} \mathrm{~cm}^{-1}$ for $6 \mathrm{~h} ;(b)$ a control gel in the absence of a field $(8 \mathrm{~h})$ where growth is nonpolarized and asynchronous. $(c, d, h, i)$ Formation of branches towards the anode in colonies pregerminated for $10 \mathrm{~h}$ without a field, then exposed to a field of $30 \mathrm{~V} \mathrm{~cm}^{-1}$ for a further $10 \mathrm{~h}(c, d)$, or exposed to a constant field of $30 \mathrm{~V} \mathrm{~cm}^{-1}$ for $24 \mathrm{~h}(h, i)$; note the spindle-shaped morphology of the colonies, due to perpendicular growth. $(e, f)$ Gels in which conidia were pregerminated for $10 \mathrm{~h}$ without a field; $(e)$ was exposed to a field of $40 \mathrm{~V} \mathrm{~cm}^{-1}$ for $4 \mathrm{~h}$ and $(f)$ incubated for the same time without any field. Stimulation of the frequency of branching in hyphae by the electrical field $(e)$ as compared to the control $(f)$ is apparent. Pregerminated hyphae can be seen bending towards the anode in a weak field $\left(5 \mathrm{~V} \mathrm{~cm}^{-1}\right)$ in $(\mathrm{g})$ (arrows indicate positions of parent conidia), or to a perpendicular plane in stronger fields in $(c)$ and $(e)$.

(Table 1 ; Fig. 7 c). At higher field strengths pregerminated hyphae of $T$. harzianum tended to grow towards the cathode but then quickly became aligned perpendicularly to the field with branches emerging to the anode (Table 1; Fig. $7 d, e$ ). In weaker fields there was a slight polarization of mature hyphae towards the cathode with concomitant branching towards the anode. 


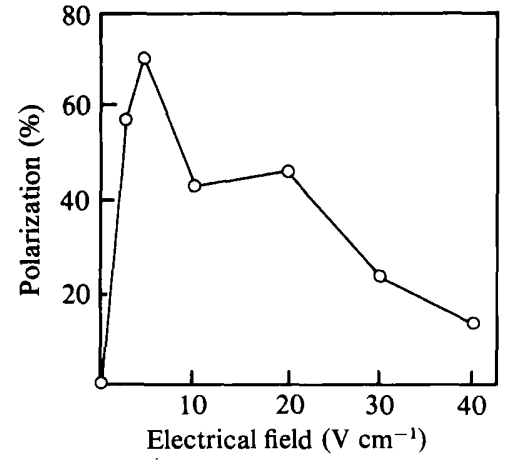

Fig. 3

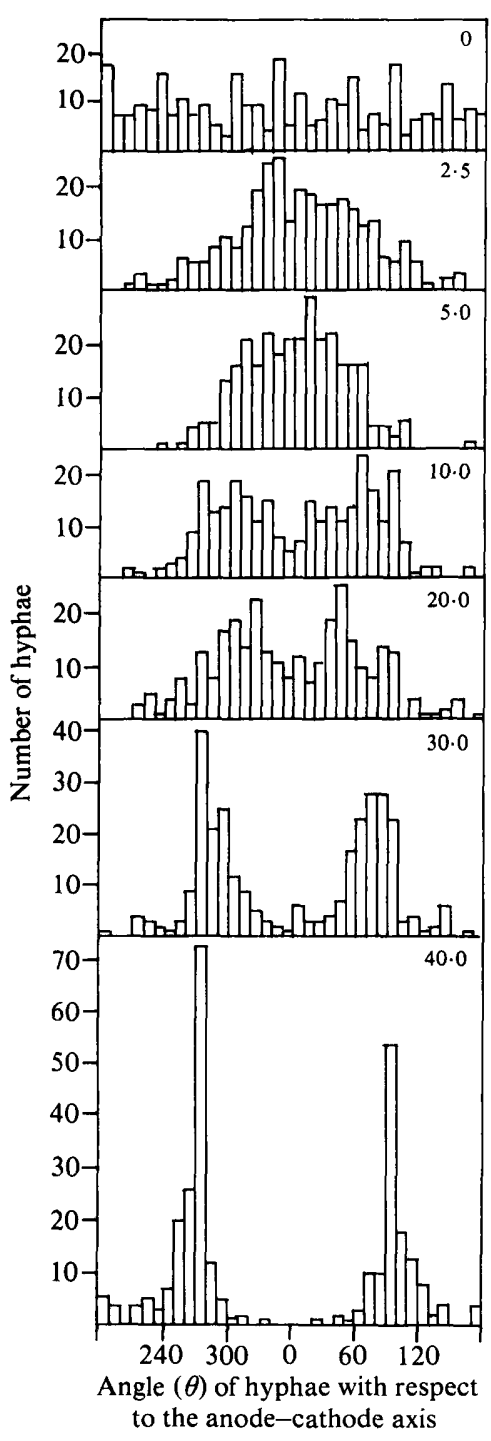

Fig. 4

Fig. 3. Polarization of hyphae (excluding branches) of $N$. crassa after $10 \mathrm{~h}$ incubation at $25^{\circ} \mathrm{C}$ in the absence of a field followed by the application of electrical fields for $5 \mathrm{~h}$.

Fig. 4. Distribution of orientations of parental hyphae (excluding hyphal branches) with respect to the anode-cathode axis in electrical fields of varying strength. The field strength $(\mathrm{V} \mathrm{cm}-1)$ is indicated in the top right-hand corner of each histogram. Data for each histogram are based on measurements of angles of 300 hyphae. Spores were allowed to germinate in the gels for $10 \mathrm{~h}$ prior to the application of an electrical field for a further $5 \mathrm{~h}$. The anode is at $0^{\circ}$, the cathode $180^{\circ}$ and the perpendicular axis $90^{\circ}$ and $270^{\circ}$. The temperature of the circulating medium was maintained at $25^{\circ} \mathrm{C}$ throughout.

The effect of exogenous electrical fields on Ach. bisexualis was studied exclusively on preparations in which the motile zoospores were allowed to encyst and germinate prior to the application of a field. This was necessary since electrical fields greatly inhibited encystment and germ tube formation in this organism. Control gels in the absence of a field showed random emergence and orientation of germ tubes (Fig. $7 f$ ), while a dramatic reorientation of germ tubes 


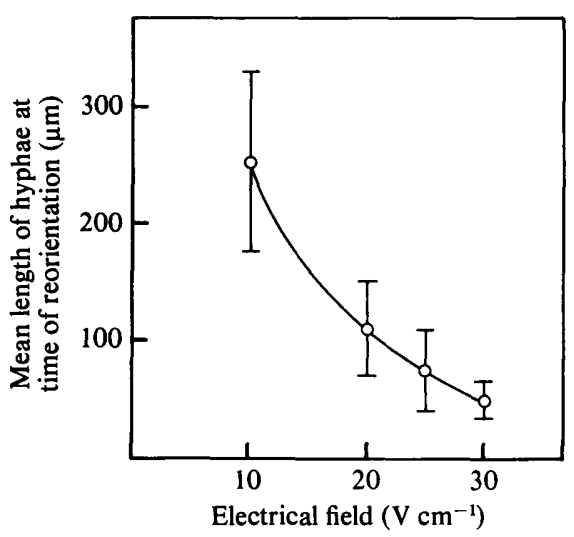

Fig. 5

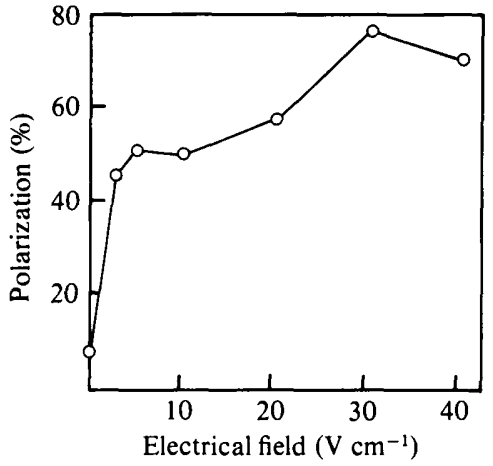

Fig. 6

Fig. 5. Relationship between the mean lengths of germ tubes of $N$. crassa at the time at which they turn from an anodotropic to a perpendicular orientation and the magnitude of the exogenous electrical field. The error bars are standard deviations from measurements of 100 hyphae.

Fig. 6. Polarization of branches of $N$. crassa towards the anode in exogenous electrical fields. Spores were allowed to germinate in the absence of a field for $10 \mathrm{~h}$, and then were exposed to electrical fields of various strengths for a further $5 \mathrm{~h}$ before the percentage polarization was determined.

Table 1. Responses of Asp. nidulans, $M$. mucedo and T. harzianum to electrical fields

\begin{tabular}{lcccr} 
& Field strength & \multicolumn{3}{c}{ Polarization, $P(\%)^{*}$} \\
\cline { 4 - 6 }$\left(\mathrm{V} \mathrm{cm}^{-1}\right)$ & Germ tubes & Hyphae & Branches \\
Asp. nidulans & 30 & $9.9 \pm 0.7$ & $-82.5 \pm 0.7$ & $-62.4 \pm 1.4$ \\
$M$. mucedo & 20 & $20.3 \pm 2.0$ & $-72.0 \pm 0.9$ & $-64.6 \pm 1.3$ \\
$T$. harzianum & 30 & ND & $-16.6 \pm 2.5$ & $32.8 \pm 0.7$ \\
& 10 & ND & $-24.9 \pm 1.0$ & $40.2 \pm 1.7$
\end{tabular}

ND, Not determined.

- For determination of the percentage polarization, see Methods. In all cases growth was nonpolarized $(P=0)$ in the absence of electrical fields.

towards the anode was observed if pregerminated colonies were exposed to an electrical field (Fig. $7 g, h$ ). This was particularly striking in sections of gels containing clumps of spores, where several germ tubes radiated from a common origin then turned to parallel anodic orientations when the electrical field was applied (Fig. $7 \mathrm{~g}$ ). Apical branching of the germ tubes was observed in some instances (Fig. 7i) but was never seen on control gels where no field was applied.

\section{DISCUSSION}

Mycelial fungi generate endogenous electrical fields which are associated with polarized tip growth. Here we show that a variety of fungi which are known to create electrical fields around themselves during polarized tip growth also respond galvanotropically in exogenous/applied electrical fields. As far as could be seen from microscopic examination of the hyphae, the cells were otherwise unaffected by the electrical fields.

The question of how endogenous and exogenous electrical fields bring about polarity is the subject of considerable debate: for recent discussions see Jaffe (1981), Nuccitelli (1983), Gow (1984), Robinson (1985) and Harold et al. $(1985 a, b)$. At least two types of mechanism have been suggested. 

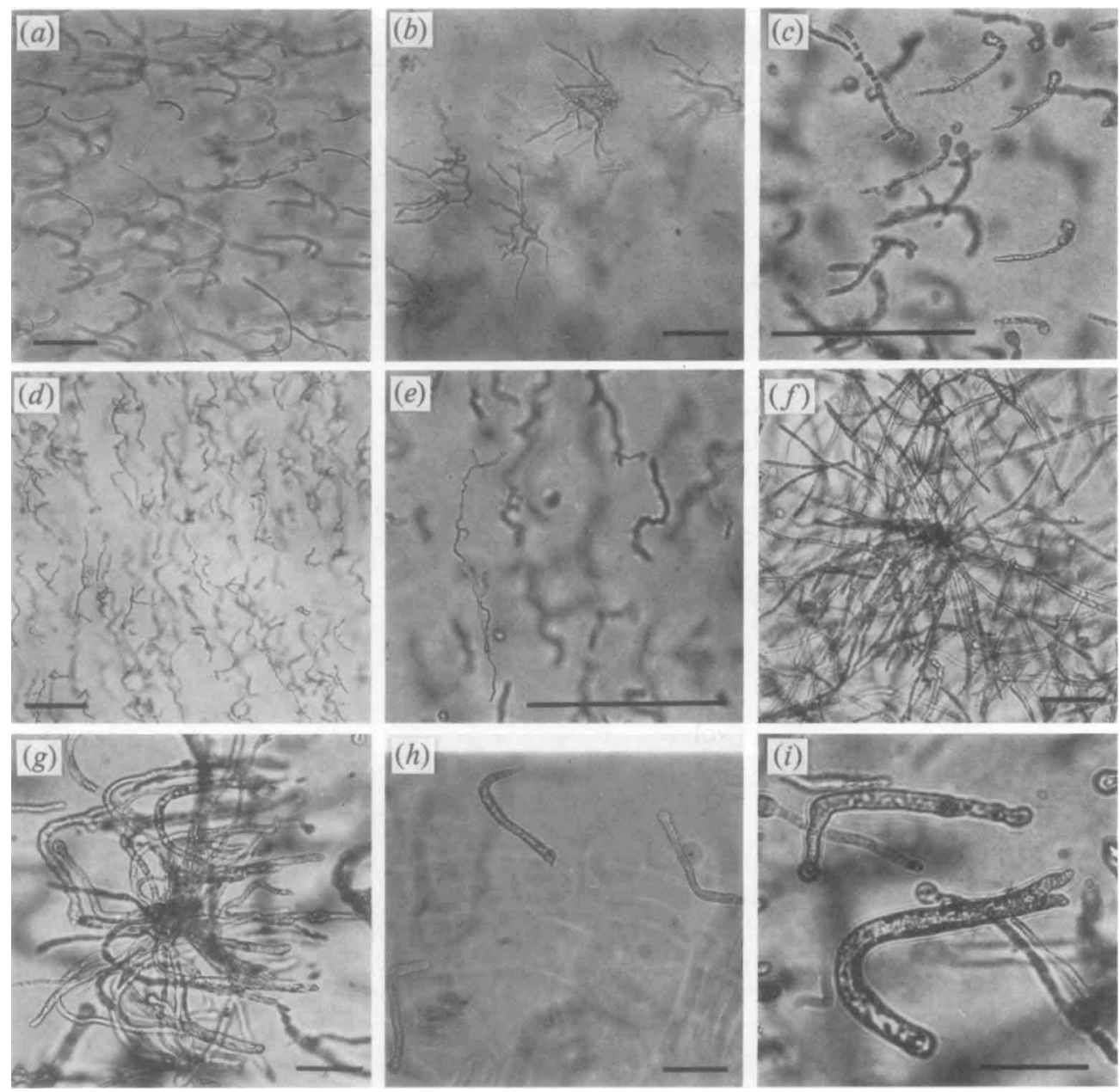

Fig. 7. Influence of applied electrical fields on Asp. nidulans $(a, b), M$. mucedo $(c), T$. harzianum $(d, e)$ and Ach. bisexualis $(f-i)$. The anode is on the right-hand side of the micrographs and the scale bars represent $100 \mu \mathrm{m} .(a, b, d)$ Cathodotropisms of hyphae and branches of $A s p$. nidulans $(a, b)$ and $M$. mucedo $(d)$ after incubation of conidia for $10 \mathrm{~h}, 30 \mathrm{~V} \mathrm{~cm}^{-1}$ and $21 \mathrm{~h}, 20 \mathrm{~V} \mathrm{~cm}-1$ respectively. $(d, e)$ Perpendicular alignment of hyphae and anodotropic formation of branches of $T$. harzianum after $16 \mathrm{~h}$ preincubation followed by $6.5 \mathrm{~h}$ exposure to an electric field of $30 \mathrm{~V} \mathrm{~cm}^{-1}$. $(f)$ Radiation of germ tubes of $A c h$. bisexualis from a clump of encysted zoospores after $17.35 \mathrm{~h}$ growth in the absence of a field, compared to polarized growth in cultures after $8.35 \mathrm{~h}$ growth without a field followed by $9 \mathrm{~h}$ exposure to a field of $15 \mathrm{~V} \mathrm{~cm}^{-1}(g, h, i)$.

Firstly, endogenous electrical fields would be capable of mobilizing and localizing charged particles such as proteins and organelles in the cytoplasm or plasmalemma by electrophoresis or electro-osmosis (Jaffe et al., 1974; Jaffe, 1977, 1981). Using intracellular microelectrodes Slayman \& Slayman (1962) and Kropf (1986) have measured cytoplasmic voltage gradients in hyphae of $N$. crassa and Ach. bisexualis which are, on a theoretical basis, strong enough to cause self-electrophoresis of soluble proteins of typical surface charge densities. Woodruff \& Telfer (1980) showed that fluorescently labelled proteins of opposite charge distributed themselves in opposite directions when they were microinjected into the cytoplasm of an embryonic tissue which was known to generate a cytoplasmic voltage across its length. Membrane-associated proteins which carry exposed charged groups could also be mobilized in electrical fields. If some of these proteins were concerned in some way with the mechanism of generation of cell polarity, 
then endogenous and exogenous electrical fields could bring about polarity by influencing the topographical distribution of these proteins. Several types of membrane proteins have been shown to become localized at a particular end of a cell if the cell is exposed to an exogenous electrical field (see Robinson, 1985). Moreover, the blockage of the free migration of one of these proteins (concanavalin A receptor protein) prevented galvanotropism of Xenopus neurites (Patel \& Poo, 1982). Exogenous electrical fields may therefore polarize mycelial fungi either by electrophoresing the proteins and membrane-bound vesicles in the cytoplasm that are required for growth or by influencing the distribution of key morphogenetic proteins in the plasmalemma. The high capacitance of biological membranes may seem to favour the latter since intracellular components would be electrically insulated from the field while perimembraneous proteins may have charged domains protruding into the periplasm which would be exposed directly to the exogenous electrical field. However, an exogenous voltage gradient applied across an elongated cell would cause a depolarization of the membrane potential on the cathode-facing side and hyperpolarization on the anodic side. Cytoplasmic voltage gradients can therefore be created by applied fields as a consequence of their perturbing effects on the membrane potential.

An alternative view of how electrical fields polarize cells emphasizes the role of the ions which flow through the intracellular voltage gradients. In Ach. bisexualis the endogenous current is carried mainly by protons (Kropf et al., 1984; Gow et al., 1984) which enter the hyphae at their growing tips. Proton influx may provide a permissive environment for local cell extension by modulating the activity of key proteins or the activity and conformation of the cytoskeleton. This type of regulation mediated through the cytoskeleton has been proposed for the inward current of calcium ions which is involved in the formation and fixation of the axis of polarity in fucoid eggs (Brawley \& Robinson, 1985). Applied fields may impinge on these types of mechanisms by altering the driving force for the influx of the specific ions at the ionic and cathodic ends of the cell through perturbation of the membrane potential at these sites.

A wide range of animal and plant cells have been shown to migrate or become polarized or aligned in electrical fields. Cultured animal cells that are capable of migration do so towards the cathode and often align themselves perpendicularly to the field while migrating (Robinson, 1985). Some plant cells, such as zygotes of Ulva and Fucus inflatus, and Equisetum spores, (Sand, 1973; Lund, 1923; Chen \& Jaffe, 1979) germinated towards the anode while zygotes of Fucus serratus formed rhizoids towards the cathode (Bentrup, 1968). Peng \& Jaffe (1976) found that 11 out of 16 batches of Pelvetia eggs formed rhizoids towards the anode, two towards the cathode and three to the cathode in weak fields and the anode in stronger fields. Analogously we find some fungi which are anodotropic (e.g. N. crassa, Ach. bisexualis), some which are cathodotropic (Asp. nidulans, M. mucedo) and others in which hyphae and branches are polarized in opposite directions (T. harzianum). As seen with many animal cell studies, orientations of longer hyphae often become perpendicular to the field. This perpendicular alignment may serve to minimize the fungistatic or fungicidal perturbations of the membrane potential of cells induced in electrical fields (Cooper \& Keller, 1984). Our data showing that hyphae bent to the perpendicular more quickly as the field strength was increased strengthen this hypothesis.

It is interesting to note that the mixed response of various fungi in applied fields contrasts with a common endogenous electrical polarity. In each of the five fungi studied here positive electrical current has been found to enter the growing hyphal apices (Kropf et al., 1983; Gow, 1984; Horwitz et al., 1984). Thus no simplistic correlation can be drawn between the polarity of the endogenous electrical fields of these fungi and their responses to external voltage gradients. Neither can we claim at this stage that the highly artificial conditions employed in our experiments in any way mimic the function of endogenous fields driven during growth in vivo. However, it is clear that electrical gradients are in themselves capable of generating polarity and that the fields that induce galvanotropism can be about as small $\left(<1 \mathrm{~V}, \mathrm{~cm}^{-1}, 1 \mathrm{mV}\right.$ per cell diameter) as the endogenous fields which have been measured in the cytoplasm of fungi such as $N$. crassa $\left(0.5 \mathrm{~V} \mathrm{~cm}^{-1}\right)$ and Ach. bisexualis $\left(0.2 \mathrm{~V} \mathrm{~cm}^{-1}\right)$ (Slayman \& Slayman, 1962; Kropf, 1986). Our observations strongly support the hypothesis that there is an electrical dimension to the control of cell polarity. 
To our knowledge the only tropic behaviours that have been described in ascomycetous and terrestrial phycomycetous fungi have been the negative autotropisms involved in the spacing of hyphae in developing mycelia and the tropisms associated with the fusion of heterothallic hyphae during the formation of sexual structures (Gooday, 1975). While chemotropism has been clearly demonstrated in Achlya species (Musgrave et al., 1977; Manavathu \& Thomas, 1985) this report may be the first to describe environmentally induced tropisms for N. crassa, Asp. nidulans, $M$. mucedo and T. harzianum.

We gratefully acknowledge financial assistance from the SERC (grant GR/D/11302) and the Aberdeen University Advisory Committee (grant 56/0112) and helpful discussions with Franklin Harold, Ruth Harold and Mark Cooper. We would also like to thank Franklin Harold for laboratory facilities for part of this work, and Heather MacKinnon and Catherine Marshall for help with preliminary experiments during their undergraduate research projects.

\section{REFERENCES}

ARMBruster, B. L. \& WeISENSEEL, M. H. (1983). Ionic currents traverse growing hyphae and sporangia of the mycelial water mould Achlya debaryana. Protoplasma 115, 65-69.

BENTRUP, F. W. (1968). Die Morphogenese pflanzlicher Zellen im elektrischen Feld. Zeitschrift für Pflanzenphysiologie 59, 309-339.

Brawley, S. H. \& Robinson, K. R. (1985). Cytochalasin treatment disrupts the endogenous currents associated with cell polarisation in fucoid zygotes: studies on the role of $\mathrm{f}$-actin in embryogenesis. Journal of Cell Biology 100, 1173-1184.

ChEN, T. H. \& JAFFe, L. F. (1979). Forced calcium entry and polarised growth of Funaria spores. Planta 144, 401-406.

COOPER, M. S. \& Keller, R. E. (1984). Perpendicular orientation and directional migration of amphibian neural crest cells in DC electrical fields. Proceedings of the National Academy of Sciences of the United States of America 81, 160-164.

De VRies, S. C. \& Wessels, J. G. H. (1982). Polarized outgrowth of hyphae by constant electrical fields during reversion of Schizophyllum commune protoplasts. Experimental Mycology 6, 95-98.

Gooday, G. W. (1975). Chemotaxis and chemotropism in fungi and algae. In Primitive Sensory and Communication Systems, pp. 155-204. Edited by M. J. Carlile. London: Academic Press.

GoodAy, G. W. (1983). The hyphal tip. In Fungal Differentiation: a Contemporary Synthesis, pp. 315356. Edited by J. E. Smith. New York: Marcel Dekker.

Gow, N. A. R. (1984). Transhyphal electrical currents in fungi. Journal of General Microbiology 130, 33133318.

Gow, N. A. R. \& McGillivray, A. M. (1986). Ion currents, electrical fields and the polarized growth of fungal hyphae. In Ionic Currents in Development (Proceedings of a Satellite Meeting to the 10th International Congress of the International Society of Developmental Biologists, University of California, Los Angeles), pp. 81-88. Edited by R. Nuccitelli. New York: Alan R. Liss Inc.

Gow, N. A. R., KROPF, D. L. \& HaRold, F. M. (1984). Growing hyphae of Achlya bisexualis generate a longitudinal $\mathrm{pH}$ gradient in the surrounding medium. Journal of General Microbiology 130, 2967-2974.
Grove, S. N. (1978). The cytology of hyphal tip growth. In The Filamentous Fungi, vol. 3, pp. 28-50. Edited by J. E. Smith and D. R. Berry. New York: Wiley.

Harold, F. M., Kropf, D. L. \& Caldwell, J. C. (1985a). Why do fungi drive electric currents through themselves? Experimental Mycology 9, 183186.

Harold, F. M., Schreurs, W. J., Harold, R. L. \& CaldWell, J. C. (1985b). Electrobiology of fungal hyphae. Microbiological Sciences 2, 363-366.

HorWITZ, B. A., Weisenseel, M. H., DoRN, A. \& GRESSEL, J. (1984). Electric currents around growing Trichoderma hyphae, before and after photoinduction of conidiation. Plant Physiology 74, 912-916.

JAFFE, L. F. (1966). Electrical currents through the developing Fucus egg. Proceedings of the National Academy of Sciences of the United States of America 56, 1102-1109.

JAFFE, L. F. (1977). Electrophoresis along cell membranes. Nature, London 265, 600-602.

JAFFE, L. F. (1966). The role of ionic currents in establishing developmental pattern. Philosophical Transactions of the Royal Society B295, 553-566.

JAFFe, L. F., Robinson, K. R. \& NuCcitelli, R. (1974). Local cation entry and self-electrophoresis as an intracellular localization mechanisms. Annals of the New York Academy of Sciences 238, 372-389.

KROPF, D. L. (1986). Cytoplasmic electric fields within growing hyphae of the water mould Achlya. Journal of Cell Biology 102, 1209-1216.

Kropf, D. L., Lupa, M. D. A., Caldwell, J. C. \& HAROLD, F. M. (1983). Cell polarity: endogenous ion currents precede and predict branching in the water mold Achlya. Science 220, 1385-1387.

Kropf, D. L., Caldwell, J. C., Gow, N. A. R. \& HAROLD, F. M. (1984). Transcellular ion currents in the water mold Achlya. Amino acid proton symport as a mechanism of current entry. Journal of Cell Biology 99, 486-496.

LUND, E. J. (1923). Electrical control of organic polarity in the egg of Fucus. Botanical Gazette 76, 288-301.

Manavathu, E. K. \& Thomas, D. D. S. (1985). Chemotropism of Achlya ambisexualis to methionine and methionyl compounds. Journal of General Microbiology 131, 751-756. 
MARSh, G. \& BEAmS, H. W. (1945). The orientation of pollen tubes of Vinca in the electric current. Journal of Cellular and Comparative Physiology 25, 195-204.

Miller, A. L., RAVEN, J. A., SPReNT, J. I. \& WeISENSEEL, M. H. (1986). Endogenous ion currents traverse growing roots and root hairs of Trifolium repens. Plant Cell and Environment 9, 79-83.

Musgrave, A., Ero, L., Scheffer, R. \& Oehlers, E. (1977). Chemotropism of Achlya bisexualis germ hyphae to casein hydrolysate and amino acids. Journal of General Microbiology 101, 65-70.

NuCCITELli, R. (1978). Ooplasmic segregation and secretion in the Pelvetia egg is accompanied by a membrane-generated electrical current. Developmental Biology 62, 13-33.

NUCCITELLI, R. (1983). Transcellular ion currents. Signals and effectors of cell polarity. Modern Cell Biology 2, 451-481.

PATel, N. \& PoO, M. M. (1982). Orientation of neurite growth by extracellular electric fields. Journal of Neurosciences 2, 483-496.

Peng, H. B. \& JAFFe, L. F. (1976). Polarization of fucoid eggs by steady electrical fields. Developmental Biology 53, 277-284.

Robinson, K. R. (1985). The responses of cells to electrical fields: a review. Journal of Cell Biology 101, 2023-2027.
Robinson, K. R. \& JAFFe, L. F. (1975). Polarizing fucoid eggs drive a calcium current through themselves. Science 187, 70-72.

SAND, O. (1973). On orientation of rhizoid outgrowth of Ulva mutabilis by applied electric fields. Experimental Cell Research 76, 444-446.

Slayman, C. L. \& Slayman, C. W. (1962). Measurements of membrane potential in Neurospora. Science 136, 876-877.

TrINCI, A. P. J. (1979). The duplication cycle and branching in fungi. In Fungal Walls and Hyphal Growth, pp. 319-358. Edited by J. H. Burnett \& A. P. J. Trinci. Cambridge: Cambridge University Press.

VoGEL, H. J. (1956). A convenient growth medium for Neurospora. Microbial Genetics Bulletin 13, 42-44.

Weisenseel, M. H., Nuccitelli, R. \& JAFFe, L. F. (1975). Large electrical currents traverse growing pollen tubes. Journal of Cell Biology 66, 556-567.

Weisenseel, M. H., DoRN, A. \& JAFFe, L. F. (1979). Natural $\mathrm{H}^{+}$currents traverse growing roots of barley (Hordeum vulgare L.). Plant Physiology 64, 512-518.

WOODRUFF, R. I. \& TelfeR, W. H. (1980). Electrophoresis of proteins in intercellular bridges. Nature, London 286, 84-86. 